Published in final edited form as:

Am J Physiol Heart Circ Physiol. 2007 November ; 293(5): H2971-H2976. doi:10.1152/ajpheart. 00219.2007.

\title{
Reactive oxygen species contribute to sleep apnea-induced hypertension in rats
}

\author{
Carmen M. Troncoso Brindeiro ${ }^{1}$, Ana Q. da Silva ${ }^{1,2}$, Kyan J. Allahdadi ${ }^{1}$, Victoria \\ Youngblood $^{1}$, and Nancy L. Kanagy ${ }^{1}$ \\ ${ }^{1}$ Department of Cell Biology and Physiology, University of New Mexico Health Sciences Center, \\ Albuquerque, New Mexico \\ 2Departamento de Fisiologia e Biofisica, Instituto de Ciencias Biologicas, Universidade Federal \\ de Minas Gerais, Belo Horizonte, Minas Gerais, Brazil
}

\begin{abstract}
In clinical studies, sleep apnea is associated with hypertension, oxidative stress, and increased circulating endothelin-1 (ET-1). We previously developed a model of sleep apnea by exposing rats to eucapnic intermittent hypoxia (IH-C) during sleep, which increases both blood pressure and plasma levels of ET-1. Because similar protocols in mice increase tissue and plasma markers of oxidative stress, we hypothesized that IH-C generation of reactive oxygen species (ROS) contributes to the development of ET-1-dependent hypertension in IH-C rats. To test this, male Sprague-Dawley rats were instrumented with indwelling blood pressure telemeters and drank either plain water or water containing the superoxide dismutase mimetic, Tempol (4hydroxy-2,2,6,6-tetramethyl-piperidine-1-oxyl, $1 \mathrm{mM}$ ). Mean arterial pressure (MAP) and heart rate (HR) were recorded for 3 control days and 14 treatment days with rats exposed $7 \mathrm{~h} / \mathrm{day}$ to IH$\mathrm{C}$ or air/air cycling (Sham). On day 14, MAP in IH-C rats treated with Tempol (107 \pm 2.29 $\mathrm{mmHg})$ was significantly lower than in untreated $\mathrm{IH}-\mathrm{C}$ rats $(118 \pm 9 \mathrm{mmHg}, P<0.05)$. Tempol did not affect blood pressure in sham-operated rats (Tempol $=101 \pm 3$, water $=101 \pm 2 \mathrm{mmHg}$ ). Immunoreactive ET-1 was greater in plasma from IH-C rats compared with plasma from shamoperated rats but was not different from Sham in Tempol-treated IH-C rats. Small mesenteric arteries from IH-C rats but not Tempol-treated IH-C rats had increased superoxide levels as measured by ferric cytochrome $c$ reduction, lucigenin signaling, and dihydroethidium fluorescence. The data show that IH-C increases ET-1 production and vascular ROS levels and that scavenging superoxide prevents both. Thus oxidative stress appears to contribute to increases in ET-1 production and elevated arterial pressure in this rat model of sleep apnea-induced hypertension.
\end{abstract}

\section{Keywords}

Tempol; endothelin

\begin{abstract}
The repeated episodes of cessation of breathing that occur during sleep apnea have been linked to the increased generation of reactive oxygen species (ROS) with an associated increase in cardiovascular morbidity (1). Since it is estimated that up to one in five adults in Western countries suffer from sleep apnea (36), this condition appears to be a significant cause of cardiovascular disease.
\end{abstract}


Several longitudinal studies of sleep apnea patients conclude that the greatest health risk of sleep apnea is the increased incidence of cardiovascular disease $(24,42)$, with the most consistent alteration being increased mean arterial pressure (MAP) $(26,30)$. Thus almost $50 \%$ of people suffering from sleep apnea also suffer from hypertension (13), and it is of great relevance to better understand the role of oxidative stress in sleep apnea-associated hypertension.

Repeated apneic episodes are reported to increase oxidative stress in sleep apnea patients $(16,21)$, in animal models of sleep apnea $(31,41)$, and in cultured cells exposed to cyclical hypoxia (43). However, debate continues on the consequences of this elevated oxidative stress. One potential consequence is an increased production of the potent vasoconstrictor, endothelin 1 (ET-1), which can be induced by ROS (18).

A role for ET-1 in sleep apnea-associated cardiovascular disease is further suggested by increased circulating plasma ET-1 $(32,44)$, which is reversed when apneic episodes are prevented with continuous positive airway pressure (17). Previously, we have shown that in rats with simulated sleep apnea, circulating plasma ET-1 increases in parallel with increases in arterial pressure and that blocking ET-1 receptors lowers MAP in these rats (20). Therefore, the mechanistic link between sleep apnea, increased ET-1 synthesis, and hypertension may be oxidative stress.

Free radicals have previously been shown to play a role in endothelial dysfunction and ET-1 synthesis in hypertension. Kaehler et al. (18) and Cheng et al. $(4,5)$ have reported that ROS, specifically superoxide, increase prepro-ET-1 promoter activity. We therefore hypothesized that ET-1 production is stimulated by increased ROS generation during the intermittent periods of hypoxia associated with sleep apnea, leading to ET-dependent systemic hypertension.

We tested this hypothesis by measuring ROS in arteries from eucapnic intermittent hypoxia (IH-C) and sham-operated rats and by scavenging ROS with the antioxidant, Tempol (4hydroxy-2,2,6,6-tetramethyl-piperidine-1-oxyl, a superoxide dismutase mimetic) during IH$\mathrm{C}$ treatment in rats and by determining the effect on blood pressure and circulating ET-1.

\section{MATERIALS AND METHODS}

\section{Animal model}

Animal protocols for this study were approved by the Institutional Animal Care and Use Committee of the University of New Mexico and follow the National Institutes of Health guidelines for animal use in research. Male Sprague-Dawley rats (200-250 g body wt; Harlan, Indianapolis, IN) were instrumented with indwelling blood pressure telemeters (DSI model PA-C40; Arden Hills, MN), allowing daily recording of MAP and heart rate (HR). Telemeter devices were sutured to the abdominal cavity wall, and the catheter tip was advanced into the abdominal aorta via the femoral artery. Control hemodynamic recordings were initiated 5 days after the surgery.

\section{Intermittent hypoxia/eucapnia protocol}

After recovery, rats $(n=26)$ were randomly divided into either IH-C $(n=15)$ or air-exposed (Sham; $n=13$ ) groups. Sham animals were exposed to the same environmental factors as IH-C, except the gas in the chamber was always air $\left(21 \% \mathrm{O}_{2}\right)$. Vehicle-treated IH-C $(n=9)$ and Sham rats $(n=7)$ drank tap water, whereas Tempol-treated rats drank water containing Tempol throughout the treatment period ( $1 \mathrm{mM}, n=6$ /group). This dose of Tempol has previously been shown to prevent increases in oxidative stress in ET-1-infused rats $(34,38)$. The atmosphere in the IH-C chamber was controlled by electronically regulated solenoid 
switches in a three-channel gas mixer, which gradually lowered oxygen in the chamber over $90 \mathrm{~s}$ from $21 \%$ to $\sim 5 \% \mathrm{O}_{2}$ and increased the $\mathrm{CO} 2$ content from $0 \%$ to $\sim 5 \%$ (Technolutions). Chambers were rapidly flushed with room air for the following $90 \mathrm{~s}$ to restore $\mathrm{O}_{2}$ to $\sim 21 \%$ and $\mathrm{CO}_{2}$ to $0 \%$. Rats were exposed to $20 \mathrm{IH}-\mathrm{C}$ cycles/h for $7 \mathrm{~h} /$ day during their sleep period for 14 days.

\section{Measurement of superoxide with ferricytochrome c}

The amount of superoxide generated in mesenteric arterioles was measured by the reduction of ferricytochrome $c$ using a kinetic spectrophotometer (DU 530; Beckman, Fullerton, CA). Reduction of ferricytochrome $c$ by $\mathrm{O}_{2}^{-}$increases absorbance at $550 \mathrm{~nm}$ and can be used as a quantitative measure of $\mathrm{O}_{2}^{-}$production (33). Absorbance at $550 \mathrm{~nm}$ was recorded every minute for $10 \mathrm{~min}$ before and $35 \mathrm{~min}$ after addition of a freshly isolated single mesenteric vascular tree to PBS containing ferricyto-chrome $c\left(5 \times 10^{-5} \mathrm{M}, \mathrm{RT}\right)$. A second branch of approximately equal weight $(0.49 \pm 0.02 \mathrm{mg}$ average $\mathrm{wt})$ was added to a second cuvette containing the SOD mimetic, tiron $(10 \mu \mathrm{M})$. The difference in $\mathrm{A}_{550}$ in the absence and presence of tiron was used to estimate $\mathrm{O}_{2}^{-}$generation/arteriole segment.

\section{Lucigenin assay}

Small mesenteric arteries were collected from rats anesthetized with pentobarbital sodium (150 mg/kg ip) on day 14 of treatment. Arteries were placed in cold physiological saline solution (PSS), (containing in $\mathrm{mM}$ ) $129.8 \mathrm{NaCl}, 5.4 \mathrm{KCl}, 0.83 \mathrm{MgSO}_{4}, 19 \mathrm{NaHCO}_{3}, 1.8$ $\mathrm{CaCl}_{2}$, and 5.5 glucose and then transferred to a test tube containing lucigenin in HEPESbuffered saline ( $1 \mathrm{mmol}, \mathrm{pH} 7.4$, room temperature). Background luminescence of the solution without arteries was subtracted from basal and NADPH-stimulated $(0.1 \mathrm{mM})$ luminescence for each sample. Measurements were normalized for the dry weight of arteries.

\section{Dihydroethidium staining}

The superoxide-sensitive fluorescent dye, dihydroethidium (DHE), was used to evaluate in situ production of superoxide. DHE is freely permeable to cells and, in the presence of $\mathrm{O}_{2}^{-}$, is oxidized to the fluorescent products, 2-hydroxyethidium and ethidium ${ }^{+}(45,46)$. DHE fluorescence is thus a qualitative way to determine relative levels of oxidative stress (45). Unfixed small mesenteric arteries from IH-C and Sham rats were rapidly frozen in optimum cutting temperature (OCT) embedding compound (TissueTek) and stored at $-70^{\circ} \mathrm{C}$ until assayed. Sections $(10 \mu \mathrm{m})$ from $\mathrm{IH}-\mathrm{C}$ and Sham arteries were thaw-mounted onto glass slides and dried $30 \mathrm{~min}$ at room temperature. Sections were then covered with DHE in PBS $(10 \mu \mathrm{M})$ and incubated $45 \mathrm{~min}$ at $37^{\circ} \mathrm{C}$. Slides were washed with PBS, and coverslips were mounted using Vectashield. Slides were analyzed on a Nikon Optiphot fluorescence microscope, using the Chroma TRITC filter set to illuminate at 510-560 nm and to collect emissions at $570-650 \mathrm{~nm}$, a range that detects primarily DNA-bound ethidium ${ }^{+}$and not the 2-OH-ethidium product of super-oxide and DHE (46). Image density was analyzed using Metamorph software. Average integrated intensities in three sections/artery were averaged from one artery per rat for four IH-C and four Sham rats.

\section{ET-1 assay}

An ET-1 selective ELISA kit (QuantiGlo; R \& D Systems, Minneapolis, MN) was used to measure the concentration of ET-1 in plasma samples collected from anesthetized IH-C and Sham animals on day 14. Blood was drawn into EGTA-coated vacutainer tubes and centrifuged at $3,000 \mathrm{~g}$ at $4^{\circ} \mathrm{C}$ for $10 \mathrm{~min}$. Plasma was stored frozen at $-70^{\circ} \mathrm{C}$ until the assay was performed. This assay employs the quantitative sandwich enzyme immunoassay technique with a monoclonal antibody specific for ET-1 precoated onto a microplate. 
Standards (0.34 to $250 \mathrm{pg} / \mathrm{ml})$ and samples were analyzed in triplicate following the instructions in the kit. The minimum detectable concentration reported by the manufacturer is $0.1 \mathrm{pg} / \mathrm{ml}$ and the average variation within samples at $3.4 \%$. In our assay with three replicates, the intra-assay precision was $8 \%$ for the standard curve and $10 \%$ for the samples, and values in control rats $(1.26 \pm 0.08 \mathrm{pg} / \mathrm{ml})$ were in the range previously reported in rats (37).

\section{Statistical analysis}

All data are expressed as means \pm SE. Data were compared using two-way repeatedmeasures analysis of variance (ANOVA) or a one-way ANOVA followed by a StudentNewman-Keul's post hoc test as appropriate (SigmaStat 3.0). Differences were considered significant for $P<0.05$.

\section{RESULTS}

\section{Hemodynamic measurements}

MAP and HR were not different during the baseline recording period between the four groups. However, after 14 days of treatment, there was a significant difference in MAP between the IH-C/vehicle group $(118 \pm 8.8 \mathrm{mmHg})$ and the other three groups: Sham/ vehicle $(101 \pm 1.7)$, Sham/Tempol $(101 \pm 3.1)$, and IH-C/Tempol $(107 \pm 2.3 \mathrm{mmHg})(\mathrm{Fig}$. 1). In the Tempol-treated IH-C rats, MAP was not significantly different from that in the Sham groups. Heart rate did not differ between any of the four groups, did not change over the time of treatment, and was not different between groups at day 14: Sham/vehicle $392 \pm$ 3.5, Sham/Tempol $372 \pm 38.7$, IH-C/vehicle $395 \pm 3.1$, and IH-C/Tempol $391 \pm 14.8$ beats/ $\min$.

\section{Superoxide generation}

Superoxide $\left(\mathrm{O}_{2}^{-}\right)$generation measured by cytochrome $c$ reduction was significantly greater in arteries from the IH-C group compared with the Sham group (Fig. 2). There was no difference between arteries from Sham and IH-C rats treated in vivo with Tempol.

\section{ROS-activated luminescence}

Basal measurements of ROS, using lucigenin as a detector, were significantly greater in arteries from the IH-C arteries than in the Sham arteries when normalized for tissue dry weight (luminescence/tissue wt in mg). NADPH stimulated a large increase in luminescence in both groups, and the difference between groups was even greater than in the absence of NADPH (Fig. 3).

\section{DHE staining}

Arteries from IH-C rats had greater DHE-induced fluorescence than arteries from Sham rats (Fig. 4). Fluorescence in arteries from IH-C rats treated with Tempol was not different from that in Sham arteries. This indicates that there is greater ROS generation in the vascular wall following 14 days of $\mathrm{IH}-\mathrm{C}$ exposure but that the increase is prevented by in vivo Tempol treatment.

\section{Plasma ET-1}

The calculated concentration of immunore-active ET-1 in plasma samples from the IH-C rats was greater than that in the Sham rat samples (Fig. 5). However, the concentration in the samples from the IH-C rats drinking Tempol-containing water was not different from that in the Sham rats. Plasma ET-1 was also not different between Sham rats drinking water and those drinking water with Tempol. Thus IH-C increases circulating ET-1, and Tempol 
specifically reduces ET-1 in IH-C rats. This suggests that Tempol prevents IH-C-induced hypertension, in part, by decreasing ET-1 synthesis.

\section{DISCUSSION}

Sleep apnea is a growing health problem in the United States, and many studies have reported a significant association between cardiovascular disease and sleep apnea $(7,14$, $15)$. Hypertension has the strongest correlation with $\sim 50 \%$ of sleep apnea patients also having hypertension (25). Because the increased risk of mortality in patients with obstructive sleep apnea (OSA) is largely from cardiovascular incidents, understanding the mechanisms underlying the cardiovascular pathology of this condition will allow more directed interventions to prevent permanent or lethal damage. Although corrective therapies to prevent the repeated apneas during sleep reduce the increased cardiovascular complications of OSA, compliance continues to be low (8), and a practical approach to further reduce cardiovascular disease in OSA patients would be to effectively treat the hypertension. Previous studies examining the mechanisms linking hypertension to OSA have shown that $\operatorname{ROS}(9,16)$ are increased in patients and in animal models of OSA $(41)$. ROS have also been associated with increased ET-1 levels and MAP. The novel findings in this study are that 1) IH-C increases MAP, plasma ET-1, and vascular ROS levels and 2) the SOD mimetic Tempol prevents the increase in MAP, oxidative stress, and plasma ET-1 in IH-C-exposed rats. Thus our data are the first to provide an in vivo association between intermittent eucapnic hypoxia, vascular ROS generation, ET-1 production, and blood pressure regulation.

We have previously shown that IH-C exposure in rats increases arterial pressure in an ET-1dependent manner (20). Furthermore, studies by Xu et al. (41) demonstrated that IH increases ROS levels in several brain regions, whereas Peng et al. (27) demonstrated an association between oxidative stress and hypertension in mice exposed to intermittent hypoxia. The current study further establishes that during IH-C exposure, in vivo generation of ROS, specifically $\mathrm{O}_{2}^{-}$, is increased and appears to be necessary to develop ET-1dependent hypertension.

In this model, rats are exposed 20 times/h to hypoxia with $\mathrm{CO}_{2}$ supplementation for $7 \mathrm{~h} /$ day, a rate comparable with the number of oxygen desaturation events in patients with moderate sleep apnea (3). This protocol differs from some experimental models of OSA that do not include exposure to $\mathrm{CO}_{2}$. In our model of IH-C, arterial pressure increases more rapidly than in studies where only IH was used (11), with a significant elevation in arterial pressure by day 10 of exposure. This is slightly slower than the increase in arterial pressure in an earlier study in which we used indwelling arterial catheters and tethers to record blood pressure (20), suggesting the stress of a tether system may accelerate the onset of hypertension. However, in both studies, maintaining eucapnia appears to accelerate the development of hypertension compared with studies where rats were exposed to hypoxia only with hyperventilation-induced hypocapnia (22). This is in contrast to studies by Fletcher and coworkers $(12,22)$, who saw no chronic effect on blood pressure by supplementing IH with $\mathrm{CO}_{2}$, a protocol similar to ours that maintains eucapnia (22). However, in the previous studies, the exposure protocol had very rapid $\mathrm{IH}$ cycling $(2$ cycles $/ \mathrm{min})$, and arterial $\mathrm{PO}_{2}$ did not return to control levels before the start of the next hypoxia exposure (2). Thus our IH-C protocol produces blood-gas changes more similar to those reported in clinical studies of OSA (6) and may be more relevant to the human condition where sleep apnea is correlated with an increased incidence of hypertension (28).

In the earlier studies by Fletcher and coworkers (12), blood pressure was recorded at day 0 and after 35 days exposure to either 120 episodes/h of hypoxia only (inspired $\mathrm{O}_{2}, 2.5 \%$ ) or 
hypoxia supplemented with $\mathrm{CO}_{2}$ ( $8 \%$ or $14 \%$ compared with $5 \%$ in our studies). These earlier studies did not measure blood pressure at earlier time points in the IH-C groups but did observe that the acute increase in blood pressure and sympathetic nerve activity was greater with IH-C than with IH exposure (22). It is therefore interesting to speculate that added $\mathrm{CO}_{2}$ may accelerate humoral and neural responses to $\mathrm{IH}$, similar to observations that hypercapnic hypoxia in humans produces a more profound activation of the sympathetic nervous system than IH only (23).

Similar to a previous study using the IH-C protocol (20), plasma ET-1 levels in untreated IH-C rats were significantly higher than in Sham rats. Furthermore, the increase in circulating ET-1 and in blood pressure during IH-C exposure was prevented by simultaneous administration of the superoxide dismutase mimetic, Tempol. In contrast, Tempol had no effect on MAP or plasma ET-1 in Sham rats. Therefore Tempol appears to counteract an IH-C-exposure effect, perhaps by eliminating ROS-stimulated ET-1 production $(5,19)$, as suggested by the measures of vascular ROS. Thus our data suggest that in vivo oxidative stress in IH-C rats, and potentially OSA patients, contributes to the development of hypertension by stimulating ET-1 synthesis.

Three separate indicators measured increased ROS production in small mesenteric arteries from IH-C rats compared with arteries from sham-operated rats. Because ET- 1 can activate NADPH oxidase (29), it is possible that elevated ET-1 stimulated ROS production in the vascular wall of IH-C rats. This would suggest the increased ROS results from ET-1 receptor activation. However, it is unclear how a feed-forward system might operate in vivo with ET-1 production both stimulated by superoxide and increasing su-peroxide production. Furthermore, the observation that the $\mathrm{O}_{2}^{-}$scavenger, Tempol, prevented both increases in circulating ET-1 and IH-C-induced increases in MAP makes it more likely that the increase in ROS is upstream of ET-1 generation rather than downstream.

Previous studies of ET-1-dependent hypertension have demonstrated that Tempol lowers blood pressure and ROS production (35), that it lowers vascular ROS production without decreasing blood pressure (10), or that it decreases blood pressure independent of its effects on superoxide production (40). For example, Xu et al. (39) suggested that Tempol decreases MAP through direct inhibition of sympathetic neurons in the cardiovascular system. This may have contributed to the decrease in the MAP we observed and would be in agreement with previous studies demonstrating that blocking the sympathetic nervous system inhibits the development of hypertension in other protocols of IH-C exposure (22). Because the in vivo treatment with Tempol lowered both the vascular ROS generation and the increases in ET-1 and MAP, the data also support the hypothesis that ROS act at the level of the vascular wall to stimulate ET-1 production, which in turn elevates MAP. Therefore, additional studies with ET-1 receptor antagonists are needed to establish which is the sequence of events.

In conclusion, the cellular mechanisms connecting sleep apnea to ROS generation and subsequent hypertension are not entirely clear. The current studies provide a novel potential link, suggesting repetitive exposures to brief periods of eucapnic hypoxia lead to increased vascular ROS generation, elevated circulating ET-1, and the development of hypertension. Thus it appears that, in this model of OSA, production of ROS contributes to both the synthesis of ET-1 and to the development of hypertension.

\section{Acknowledgments}

This study was supported by NIH Grants PA-5642 and HL-03852.

\section{GRANTS}


N. L. Kanagy is an Established Investigator of the American Heart Association and C. M. Troncoso Brindeiro was a MARK-U-STAR Fellow through the National Institutes of Health (NIH). Special thanks to Roma Kalra for assistance with the endothelin assay.

\section{References}

1. Baguet JP, Narkiewicz K, Mallion JM. Update on Hypertension Management: obstructive sleep apnea and hypertension. J Hypertens. 2006; 24:205-208. [PubMed: 16331122]

2. Bao G, Randhawa PM, Fletcher EC. Acute blood pressure elevation during repetitive hypocapnic and eucapnic hypoxia in rats. J Appl Physiol. 1997; 82:1071-1078. [PubMed: 9104841]

3. Boland LL, Shahar E, Iber C, Knopman DS, Kuo TF, Nieto FJ. Measures of cognitive function in persons with varying degrees of sleep-disordered breathing: the Sleep Heart Health Study. J Sleep Res. 2002; 11:265-272. [PubMed: 12220323]

4. Cheng TH, Cheng PY, Shih NL, Chen IB, Wang DL, Chen JJ. Involvement of reactive oxygen species in angiotensin II-induced endothelin-1 gene expression in rat cardiac fibroblasts. J Am Coll Cardiol. 2003; 42:1845-1854. [PubMed: 14642698]

5. Cheng TH, Shih NL, Chen SY, Loh SH, Cheng PY, Tsai CS, Liu SH, Wang DL, Chen JJ. Reactive oxygen species mediate cyclic strain-induced endothelin-1 gene expression via Ras/Raf/ extracellular signal-regulated kinase pathway in endothelial cells. J Mol Cell Cardiol. 2001; 33:1805-1814. [PubMed: 11603923]

6. Chin K, Hirai M, Kuriyama T, Fukui M, Kuno K, Sagawa Y, Ohi M. Changes in the arterial $\mathrm{PCO}_{2}$ during a single night's sleep in patients with obstructive sleep apnea. Intern Med. 1997; 36:454 460. [PubMed: 9240492]

7. Coccagna G, Pollini A, Provini F. Cardiovascular disorders and obstructive sleep apnea syndrome. Clin Exp Hypertens. 2006; 28:217-224. [PubMed: 16833027]

8. Dong X, He Q, Han F, Wei H, Chen E, Ding D. The compliance with nasal continuous positive airway pressure in patients with sleep apnea syndrome. Zhonghua Jie He He Hu Xi Za Zhi. 2002; 25:399-402. [PubMed: 12435297]

9. Dyugovskaya L, Lavie P, Lavie L. Increased adhesion molecules expression and production of reactive oxygen species in leukocytes of sleep apnea patients. Am J Respir Crit Care Med. 2002; 165:934-939. [PubMed: 11934717]

10. Elmarakby AA, Loomis ED, Pollock JS, Pollock DM. NADPH oxidase inhibition attenuates oxidative stress but not hypertension produced by chronic ET-1. Hypertension. 2005; 45:283-287. [PubMed: 15623539]

11. Fletcher EC. Cardiovascular consequences of obstructive sleep apnea: experimental hypoxia and sympathetic activity. Sleep. 2000; 23(Suppl 4):S127-S131. [PubMed: 10893085]

12. Fletcher EC, Bao G, Miller CC 3rd. Effect of recurrent episodic hypocapnic, eucapnic, and hypercapnic hypoxia on systemic blood pressure. J Appl Physiol. 1995; 78:1516-1521. [PubMed: 7615464]

13. Haas DC, Foster GL, Nieto FJ, Redline S, Resnick HE, Robbins JA, Young T, Pickering TG. Agedependent associations between sleep-disordered breathing and hypertension: importance of discriminating between systolic/diastolic hypertension and isolated systolic hypertension in the Sleep Heart Health Study. Circulation. 2005; 111:614-621. [PubMed: 15699282]

14. Hiestand DM, Britz P, Goldman M, Phillips B. Prevalence of symptoms and risk of sleep apnea in the US population: results from the national sleep foundation sleep in America 2005 poll. Chest. 2006; 130:780-786. [PubMed: 16963675]

15. Hossain JL, Shapiro CM. The prevalence, cost implications, and management of sleep disorders: an overview. Sleep Breath. 2002; 6:85-102. [PubMed: 12075483]

16. Jordan W, Cohrs S, Degner D, Meier A, Rodenbeck A, Mayer G, Pilz J, Ruther E, Kornhuber J, Bleich S. Evaluation of oxidative stress measurements in obstructive sleep apnea syndrome. J Neural Transm. 2006; 113:239-254. [PubMed: 15959848]

17. Jordan W, Reinbacher A, Cohrs S, Grunewald RW, Mayer G, Ruther E, Rodenbeck A. Obstructive sleep apnea: plasma endothelin-1 precursor but not endothelin-1 levels are elevated and decline with nasal continuous positive airway pressure. Peptides. 2005; 26:1654-1660. [PubMed: 16112406] 
18. Kaehler J, Sill B, Koester R, Mittmann C, Orzechowski HD, Muenzel T, Meinertz T. Endothelin-1 mRNA and protein in vascular wall cells is increased by reactive oxygen species. Clin Sci (Lond). 2002; 103(Suppl 48):176S-178S. [PubMed: 12193080]

19. Kahler J, Ewert A, Weckmuller J, Stobbe S, Mittmann C, Koster R, Paul M, Meinertz T, Munzel T. Oxidative stress increases endothelin-1 synthesis in human coronary artery smooth muscle cells. J Cardiovasc Pharmacol. 2001; 38:49-57. [PubMed: 11444502]

20. Kanagy NL, Walker BR, Nelin LD. Role of endothelin in intermittent hypoxia-induced hypertension. Hypertension. 2001; 37:511-515. [PubMed: 11230327]

21. Lavie L, Vishnevsky A, Lavie P. Evidence for lipid peroxidation in obstructive sleep apnea. Sleep. 2004; 27:123-128. [PubMed: 14998248]

22. Lesske J, Fletcher EC, Bao G, Unger T. Hypertension caused by chronic intermittent hypoxiainfluence of chemoreceptors and sympathetic nervous system. J Hypertens. 1997; 15:1593-1603. [PubMed: 9488210]

23. Morgan BJ, Crabtree DC, Palta M, Skelton MM. Combined hypoxia and hypercapnia evokes longlasting sympathetic activation in humans. J Appl Physiol. 1995; 79:205-213. [PubMed: 7559221]

24. Newman AB, Nieto FJ, Guidry U, Lind BK, Redline S, Pickering TG, Quan SF. Relation of sleepdisordered breathing to cardiovascular disease risk factors: the Sleep Heart Health Study. Am J Epidemiol. 2001; 154:50-59. [PubMed: 11434366]

25. Nieto FJ, Young TB, Lind BK, Shahar E, Samet JM, Redline S, D’Agostino RB, Newman AB, Lebowitz MD, Pickering TG. Association of sleep-disordered breathing, sleep apnea, and hypertension in a large community-based study. Sleep Heart Health Study. JAMA. 2000; 283:1829-1836. [PubMed: 10770144]

26. Peker Y, Hedner J, Norum J, Kraiczi H, Carlson J. Increased incidence of cardiovascular disease in middle-aged men with obstructive sleep apnea: a 7-year follow-up. Am J Respir Crit Care Med. 2002; 166:159-165. [PubMed: 12119227]

27. Peng YJ, Yuan G, Ramakrishnan D, Sharma SD, Bosch-Marce M, Kumar GK, Semenza GL, Prabhakar NR. Heterozygous HIF-1alpha deficiency impairs carotid body-mediated systemic responses and reactive oxygen species generation in mice exposed to intermittent hypoxia. J Physiol. 2006; 577:705-716. [PubMed: 16973705]

28. Peppard PE, Young T, Palta M, Skatrud J. Prospective study of the association between sleepdisordered breathing and hypertension. N Engl J Med. 2000; 342:1378-1384. [PubMed: 10805822]

29. Pollock DM, Pollock JS. Endothelin and oxidative stress in the vascular system. Curr Vasc Pharmacol. 2005; 3:365-367. [PubMed: 16248780]

30. Quan SF, Gersh BJ. Cardiovascular consequences of sleep-disordered breathing: past, present and future: report of a workshop from the National Center on Sleep Disorders Research and the National Heart, Lung, and Blood Institute. Circulation. 2004; 109:951-957. [PubMed: 14993147]

31. Row BW, Liu R, Xu W, Kheirandish L, Gozal D. Intermittent hypoxia is associated with oxidative stress and spatial learning deficits in the rat. Am J Respir Crit Care Med. 2003; 167:1548-1553. [PubMed: 12615622]

32. Saarelainen S, Seppala E, Laasonen K, Hasan J. Circulating endothe-lin-1 in obstructive sleep apnea. Endothelium. 1997; 5:115-118. [PubMed: 9237045]

33. Sato A, Sakuma I, Gutterman DD. Mechanism of dilation to reactive oxygen species in human coronary arterioles. Am J Physiol Heart Circ Physiol. 2003; 285:H2345-H2354. [PubMed: 14613909]

34. Schnackenberg CG, Wilcox CS. Two-week administration of Tempol attenuates both hypertension and renal excretion of 8-Iso prostaglandin f2alpha. Hypertension. 1999; 33:424-428. [PubMed: 9931141]

35. Sedeek MH, Llinas MT, Drummond H, Fortepiani L, Abram SR, Alexander BT, Reckelhoff JF, Granger JP. Role of reactive oxygen species in endothelin-induced hypertension. Hypertension. 2003; 42:806-810. [PubMed: 12874096]

36. Tishler PV, Larkin EK, Schluchter MD, Redline S. Incidence of sleep-disordered breathing in an urban adult population: the relative importance of risk factors in the development of sleepdisordered breathing. JAMA. 2003; 289:2230-2237. [PubMed: 12734134] 
37. Wang H, Galligan JJ, Fink GD. The role of ETA receptor binding in the net nonhepatic splanchnic release (nNHSR) of endothelin-1 in DOCA-salt hypertensive rats. FASEB J. 2005; 19:A733A734.

38. Welch WJ, Mendonca M, Blau J, Karber A, Dennehy K, Patel K, Lao YS, Jose PA, Wilcox CS. Antihypertensive response to prolonged Tempol in the spontaneously hypertensive rat. Kidney Int. 2005; 68:179-187. [PubMed: 15954907]

39. Xu H, Fink GD, Galligan JJ. Nitric oxide-independent effects of Tempol on sympathetic nerve activity and blood pressure in DOCA-salt rats. Am J Physiol Heart Circ Physiol. 2002; 283:H885H892. [PubMed: 12181115]

40. Xu H, Fink GD, Galligan JJ. Tempol lowers blood pressure and sympathetic nerve activity but not vascular O2- in DOCA-salt rats. Hypertension. 2004; 43:329-334. [PubMed: 14707156]

41. Xu W, Chi L, Row BW, Xu R, Ke Y, Xu B, Luo C, Kheirandish L, Gozal D, Liu R. Increased oxidative stress is associated with chronic intermittent hypoxia-mediated brain cortical neuronal cell apoptosis in a mouse model of sleep apnea. Neuroscience. 2004; 126:313-323. [PubMed: 15207349]

42. Yaggi H, Mohsenin V. Sleep-disordered breathing and stroke. Clin Chest Med. 2003; 24:223-237. [PubMed: 12800780]

43. Yuan G, Adhikary G, McCormick AA, Holcroft JJ, Kumar GK, Prabhakar NR. Role of oxidative stress in intermittent hypoxia-induced immediate early gene activation in rat PC12 cells. J Physiol. 2004; 557:773-783. [PubMed: 15107478]

44. Zamarron-Sanz C, Ricoy-Galbaldon J, Gude-Sampedro F, Riveiro-Riveiro A. Plasma levels of vascular endothelial markers in obstructive sleep apnea. Arch Med Res. 2006; 37:552-555. [PubMed: 16624658]

45. Zhao H, Joseph J, Fales HM, Sokoloski EA, Levine RL, Vasquez-Vivar J, Kalyanaraman B. Detection and characterization of the product of hydroethidine and intracellular superoxide by HPLC and limitations of fluorescence. Proc Natl Acad Sci USA. 2005; 102:5727-5732. [PubMed: 15824309]

46. Zhao H, Kalivendi S, Zhang H, Joseph J, Nithipatikom K, Vásquez-Vivar J, Kalyanaraman B. Superoxide reacts with hydroethidine but forms a fluorescent product that is distinctly different from ethidium: potential implications in intracellular fluorescence detection of superoxide. Free Radic Biol Med. 2003; 34:1359-1368. [PubMed: 12757846] 


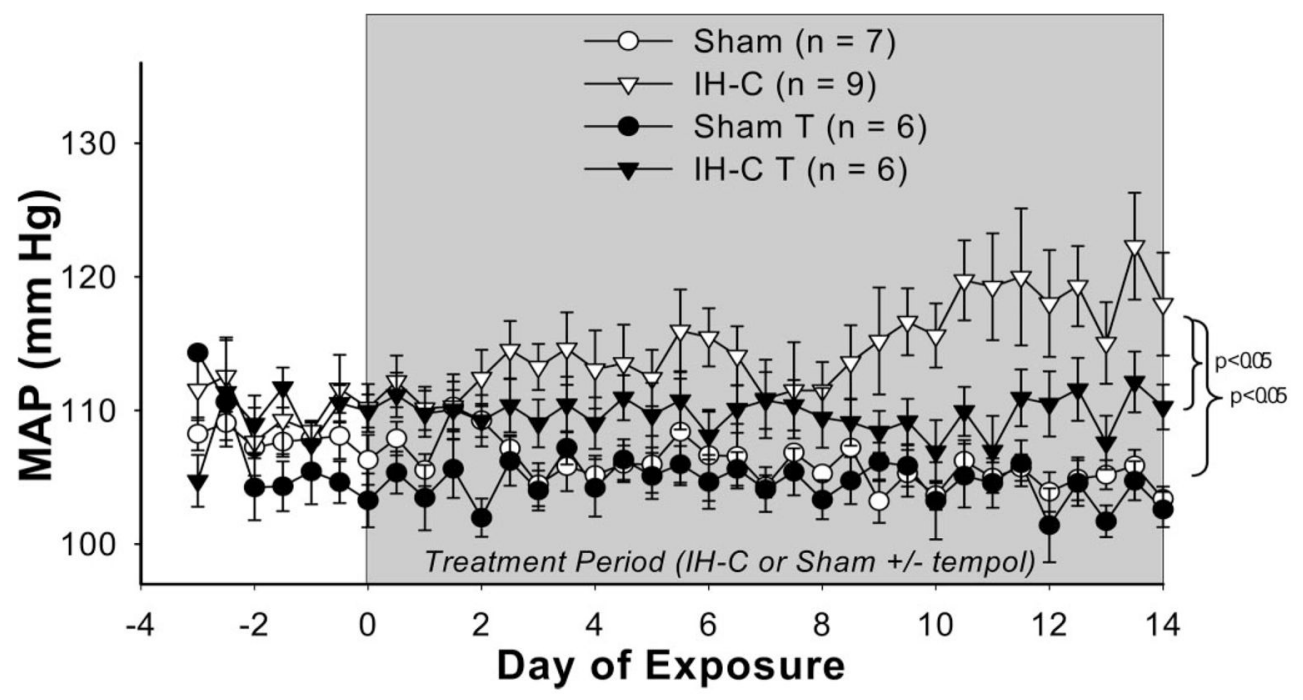

Fig. 1.

Mean arterial blood pressure (MAP) was recorded daily for 3 baseline days and 14 treatment days in eucapnic intermittent hypoxia (IH-C) \pm Tempol and Sham \pm Tempol (T). MAP increased in IH-C-vehicle rats over the 14 days of treatment. MAP did not increase in IH-C rats treated with Tempol $(1 \mathrm{mM})$. Tempol did not affect MAP in sham-operated rats. ${ }^{*} P<$ 0.05 , significant difference from Sham/vehicle. 

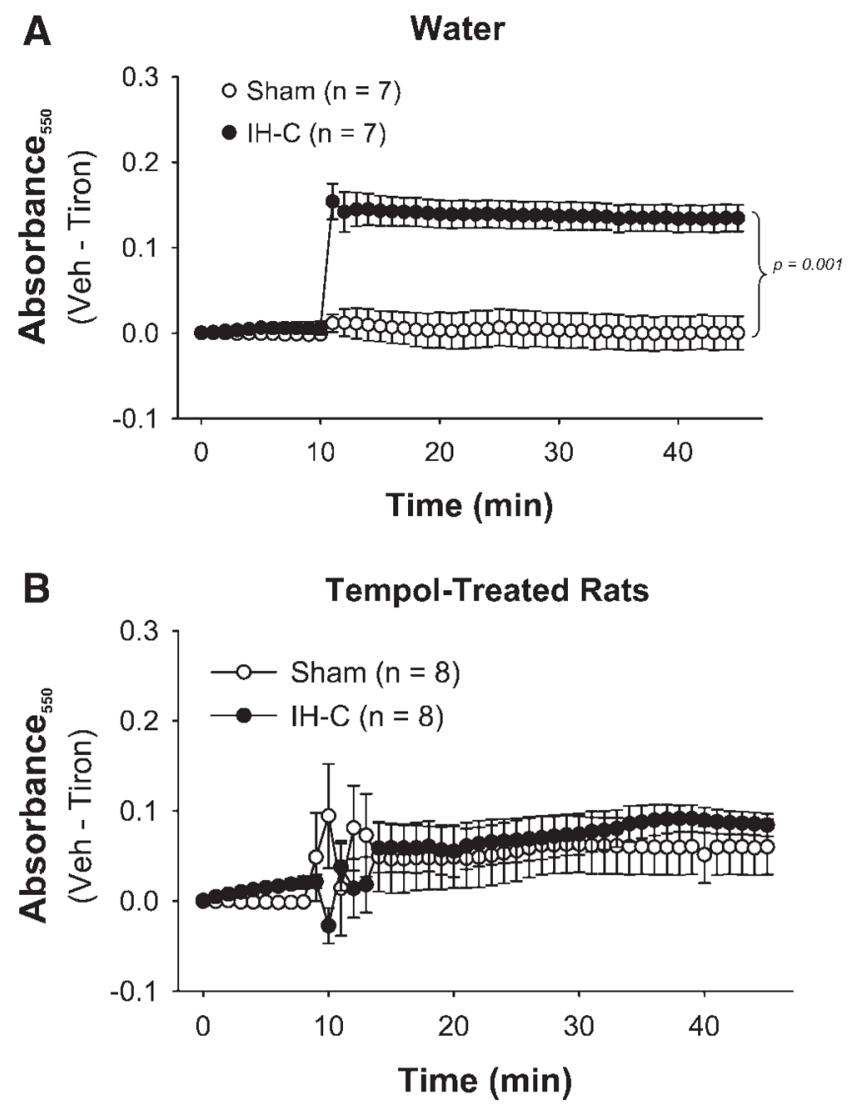

Fig. 2.

Tiron-sensitive $O_{2}^{-}$generation measured as change in absorbance at $550 \mathrm{~nm}\left(\mathrm{~A}_{550}\right)$ of a ferric cytochrome $c$ solution was greater in mesenteric arteries from 14-day IH-C rats $(A)$ than in arteries from 14-day Sham rats but not in arteries from IH-C rats treated with Tempol $(B)$ compared with arteries from Sham rats treated with Tempol. Data presented are vehicle (Veh) $\mathrm{A}_{550}$-tiron-insensitive $\mathrm{A}_{550}$. 


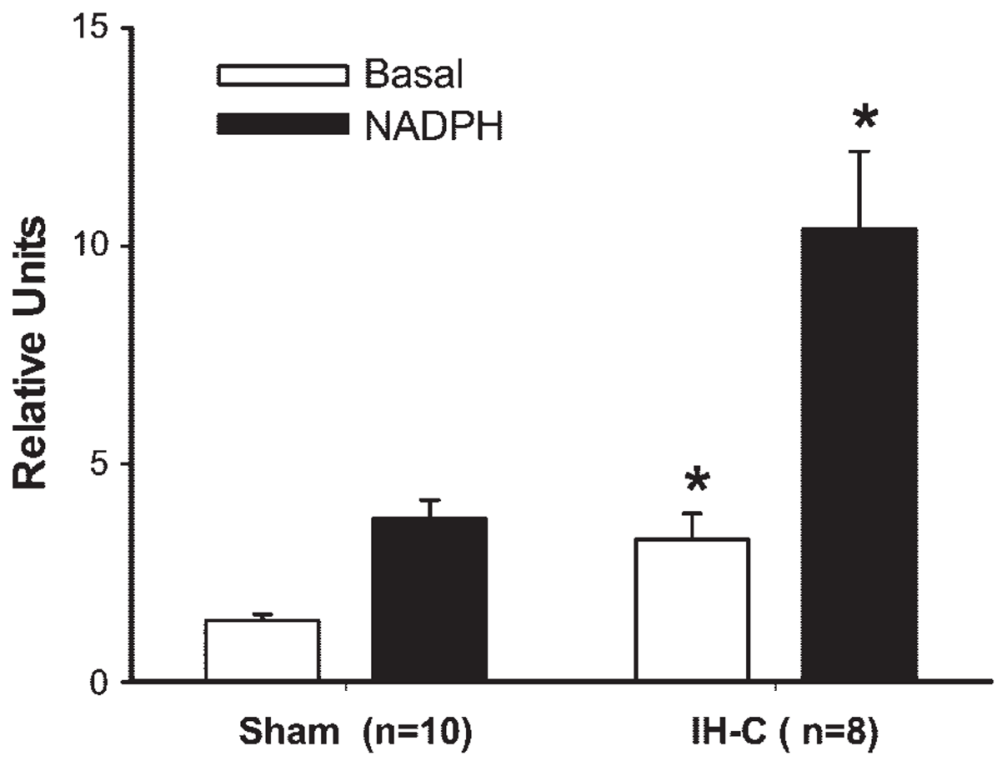

Fig. 3.

Basal and NADPH-stimulated lucigenin luminescence was greater in mesenteric arteries from IH-C rats $(n=8)$ than in arteries from Sham rats $(n=10) . * P<0.05$, significant difference from Sham. 

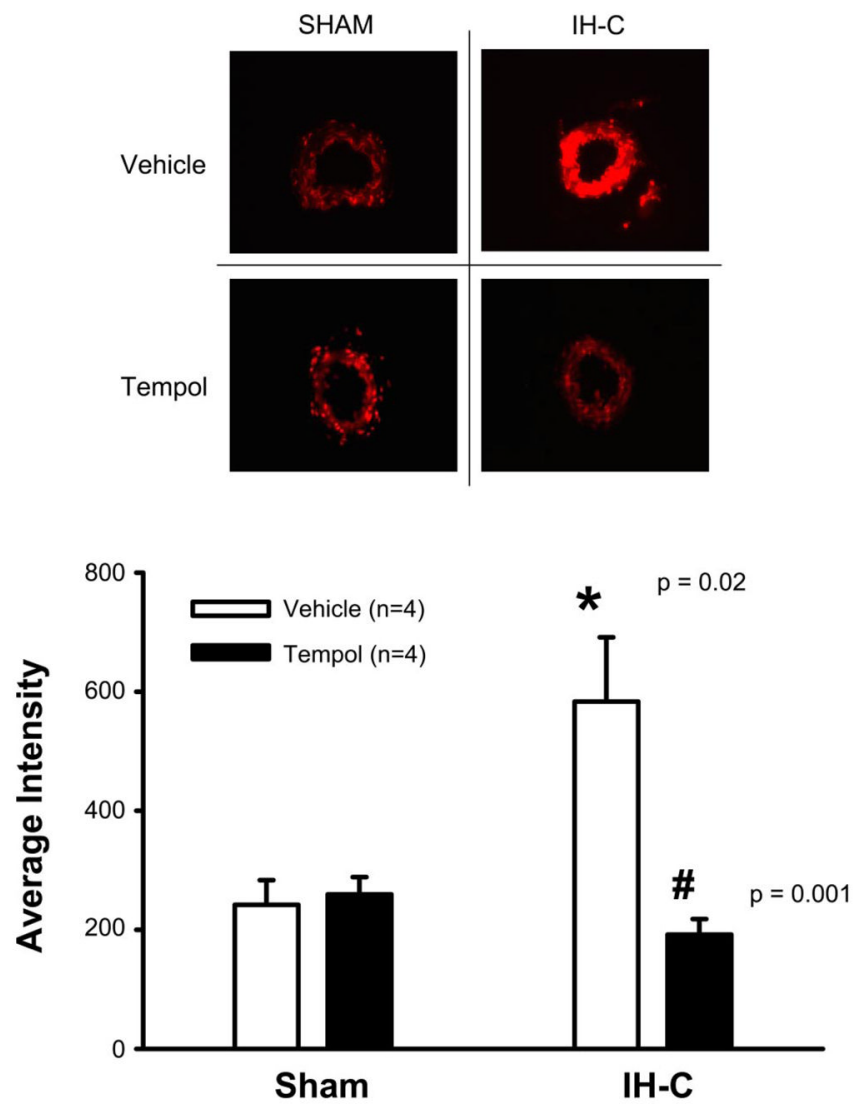

Fig. 4.

Dihydroethidium fluorescence was greater in IH-C arteries than in Sham arteries. Tempol treatment in vivo prevented the IH-C-stimulated increase but did not affect the signal in arteries from Sham rats. *Significant difference from Sham; \#Significant difference from vehicle within group. 


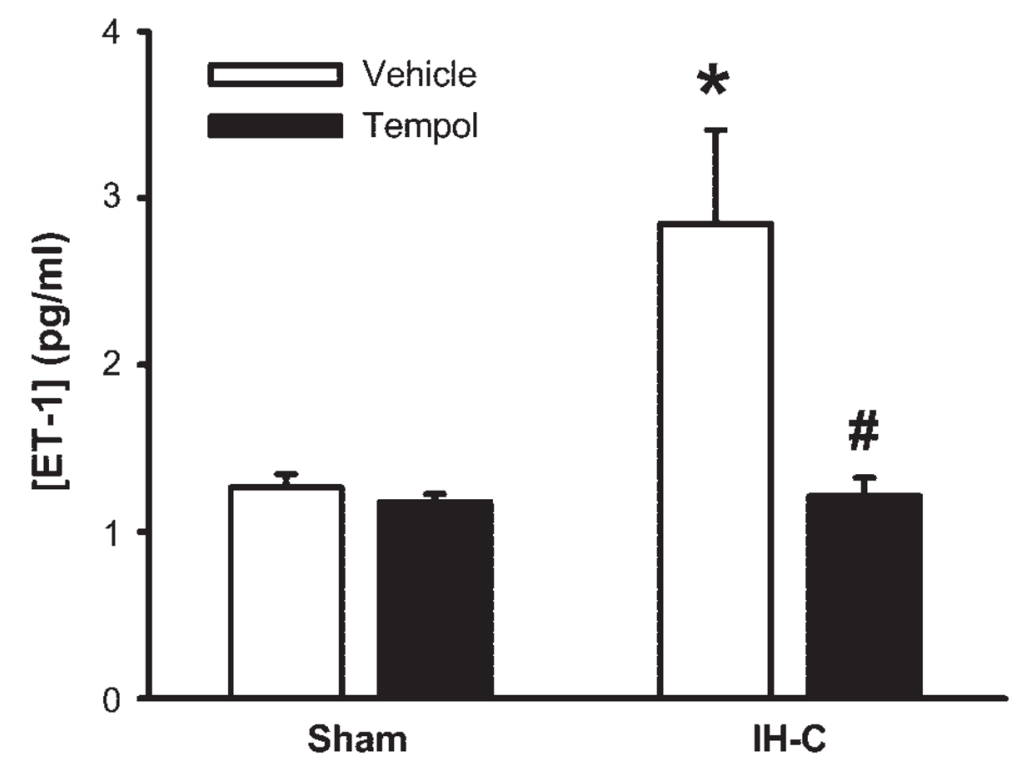

Fig. 5.

Plasma concentration of endothelin (ET-1) in blood samples taken from rats exposed to 14 days of either Sham or IH-C cycling and drinking either tap water or water containing Tempol (1 mmol/l). [ET-1] was significantly greater in plasma from IH-C rats compared with plasma from sham-operated rats and plasma from Tempol-treated IH-C rats $(P<0.05)$. *Significant difference from Sham; \#Significant difference from vehicle within group. 